Seeing the City 


\section{Seeing the City}

\section{Interdisciplinary Perspectives on the Study of the Urban}

Edited by:

Nanke Verloo

Luca Bertolini 


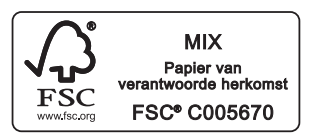

Volume 6 of the Series Perspectives on Interdisciplinarity

Cover illustration: Photo by Nanke Verloo

Cover design and lay-out: Matterhorn Amsterdam

$\begin{array}{ll}\text { ISBN } & 9789463728942 \\ \text { e-ISBN } & 9789048553099 \\ \text { DOI } & \text { I0.5II7/9789463728942 } \\ \text { NUR } & 740\end{array}$

(C) Nanke Verloo \& Luca Bertolini / Amsterdam University Press B.V., Amsterdam 2020

All rights reserved. Without limiting the rights under copyright reserved above, no part of this book may be reproduced, stored in or introduced into a retrieval system, or transmitted, in any form or by any means (electronic, mechanical, photocopying, recording or otherwise) without the written permission of both the copyright owner and the author of the book.

Every effort has been made to obtain permission to use all copyrighted illustrations reproduced in this book. Nonetheless, whosoever believes to have rights to this material is advised to contact the publisher. 


\section{Contents}

$\begin{array}{ll}\text { Acknowledgments } & 10\end{array}$

1 Introduction 12

Nanke Verloo and Luca Bertolini

$\begin{array}{ll}\text { Seeing the city } & 15\end{array}$

Seeing Amsterdam 18

Seeing this volume 19

References $\quad 21$

2 Quantitative data collection: A meta view 22

Willem Boterman

Introduction $\quad 22$

Origins of quantitative data collection and uses: the census 23

Collecting survey data $\quad 24$

Administrative data $\quad 28$

Big data $\quad 31$

Conclusion $\quad 33$

References $\quad 34$

3 Urban ethnography and participant observations:

Studying the city from within

\section{Nanke Verloo}

Why studying the city from within?

'Thick description', limitations, and underlying assumptions 39

Preparing for ethnographic fieldwork $\quad 40$

Doing fieldwork $\quad 44$

Representing and interpreting ethnographic data $\quad 47$

Reflectivity and positionality $\quad 50$

Conclusions $\quad 52$

References 53 
4 Sensing the city through new forms of urban data

Achilleas Psyllidis

Introduction

Physical sensor data

58

Mobile phone data

59

Social media data

61

User-generated \& POI-based web data

63

Summary

64

References

5 Interviewing in urban research

Fenne M. Pinkster

Introduction

The purpose of interviewing

71

Developing the methodology: research sample

Constructing an interview guide

73

Ethical considerations and interview protocol

78

Going into the field

78

The art of interviewing

80

Processing your data while in the field

82

Conclusion

83

References

6 Digging in the crates: Archival research and historical primary sources

Tim Verlaan

Introduction

85

What is an archive, and what lurks inside?

86

Setting foot in murky waters 88

Conclusion $\quad 93$

References 94

7 Reading spaces: A cultural analysis approach 96

Daan Wesselman

Object selection, research questions, and analytical toolkit

Analyzing aesthetics and discourse 101

Reflection 106

General conclusion $\quad 107$

References 108 
8 The practice of institutional analysis in urban contexts

Federico Savini

Objectives and motives of institutional analysis

Distinguishing and connecting levels of analysis departing from institutional tensions

Setting operational grids to set up the analysis

Gathering and analyzing data in a targeted way

The challenges of institutional analysis

References

9 Household preferences and hedonic pricing

Hans R.A. Koster and Jan Rouwendal

Introduction

Micro-economic foundations

Econometric estimation of hedonic price functions

Summary

References

10 Urban research in another dimension: methods for modelling historical cities

Claartje Rasterhoff

Introduction

Mapping and modeling methods

From dusty old archives to fuzzy new data

Urban mapping and models

Conclusion

References

11 Mapping the city: Geographic Information Systems and science in urban research

\section{Rowan Arundel}

Introduction: space matters

Geographic Information Science and Systems

Applying a GIS approach to research

Conclusion

References 
12 Methods for studying urban biodiversity

Gerard Oostermeijer

Introduction

Describing biodiversity $\quad 181$

General conclusions $\quad 190$

References 192

\section{Action research in the city: developing}

collaborative governance arrangements for the urban commons

\section{Joachim Meerkerk and Stan Majoor}

Introduction: Making the city together through action research

196

Performing action research: Becoming a contributive actor

198

Using a conceptual model to foster systemic transformation 206

Conclusions 209

References 209

14 Streetlabs as a co-creative approach

to Research Through Design

STBY (Nina Stegeman, Geke van Dijk, Bas Raijmakers)

Introduction

Streetlabs: a co-creative and collaborative approach

213

Initial exploration and reframing 214

Streetlab Facilitation $\quad 216$

Orchestrating conversations around current situation (AS IS)

and future situation (TO BE) 218

Documentation and analysis of the stories and ideas collected 221

Delivering the results $\quad 222$

Implementation \& Reflection 223

Recommendations for further reading 225

\section{Too many cities in the city?}

Interdisciplinary and transdisciplinary city research methods and the challenge of integration

\section{Machiel Keestra and Nanke Verloo}

Introduction: Interdisciplinary, transdisciplinary and action

research of a city in lockdown

Setting the stage: establishing an ID/TD research team 229

Integrating disciplinary perspectives

Interdisciplinary research as an iterative process

of mutual learning

References 
16 Exploring city science

Caroline Nevejan

Introduction

243

The need for city science

244

Current collaborations between cities and universities

246

Research, Policy and Design

249

City science, the research process

249

Research design

253

Discussion and future research

263

References

264

17 Conclusions

266

Luca Bertolini and Nanke Verloo

What did we see and understand?

266

How did we progress?

268

What did we miss?

269

Agenda for Urban Research

Glossary

List of contributors 


\section{Acknowledgments}

This edited volume is the product of a long journey that brought together a wide variety of Amsterdam-based scholars, all of whom study the city within their respective disciplines. Inter- or transdisciplinary work is only possible if we allow ourselves to open our minds to different views and interpretations: it demands that we look beyond boundaries that are often taken for granted, and on top of that it requires us to engage with others and form collaborative networks. In the first place, we are therefore indebted to our authors, who brought such open-mindedness to their participation in the various author workshops, and whose knowledge and efforts were indispensable for making this volume a success. We are more than grateful to them for helping us to develop a collaborative community of scholars who were willing and able to engage in all these facets of inter- and transdisciplinary work.

This book is part of the University of Amsterdam (UvA) Institute for Interdisciplinary Studies (IIS) series 'Perspectives on Interdisciplinarity', which has made significant contributions to scholarship on interdisciplinary studies and beyond. The book would not have seen the light of day without the knowledge and experience of the IIS, and specifically the efforts of Yorike Hartman and Lucy Wenting, who supported us throughout the process and contributed constructive feedback every step of the way. And we would like to acknowledge Katusha Sol from the IIS who first initiated the idea. 
We are also grateful for the contribution of the interdisciplinary Scientific Board, who provided us with ideas and critical commentaries at various points in the process and who reviewed drafts and gave useful feedback on individual chapters. Each session with the academic board replenished our thinking and helped us move forward. Its members are Prof. Dr. Ir. A. Bozzon (Professor of Human-Centered Artificial Intelligence, Department of Design Engineering, Faculty of Industrial Design Engineering, TU Delft); Prof. Dr. J. Grin (Professor of Policy Science, Department of Political Science, University of Amsterdam); Prof. Dr. R. Jaffe (Professor of Urban Geography, Department of Human Geography, Planning and International Development Studies and the Centre for Urban Studies, University of Amsterdam); Prof. Dr. C.I.M. Nevejan (Professor by special appointment, Amsterdam School for Social Science Research, University of Amsterdam, and Chief Science Officer of the city of Amsterdam); Prof. Dr. J.J. Noordegraaf (Professor of Digital Heritage, Department of Media Studies, University of Amsterdam); Prof. Dr. K. Pfeffer (Professor of Infrastructuring Urban Futures, University of Twente); Prof. Dr. P.M.A. Sloot (Professor of Complex Adaptive Systems and Scientific Director Institute for Advanced Studies, University of Amsterdam); and Prof. Dr. E.T. Verhoef (Professor of Spatial Economics, School of Business and Economics, Free University Amsterdam).

Finally, we would like to recognize the IIS and the Centre for Urban Studies (CUS), who provided us with the resources to work on this edited volume, and the team at Amsterdam University Press, whose support in finalizing the manuscript and preparing it for publication is greatly appreciated. 


\section{Introduction}

\section{Nanke Verloo and Luca Bertolini}

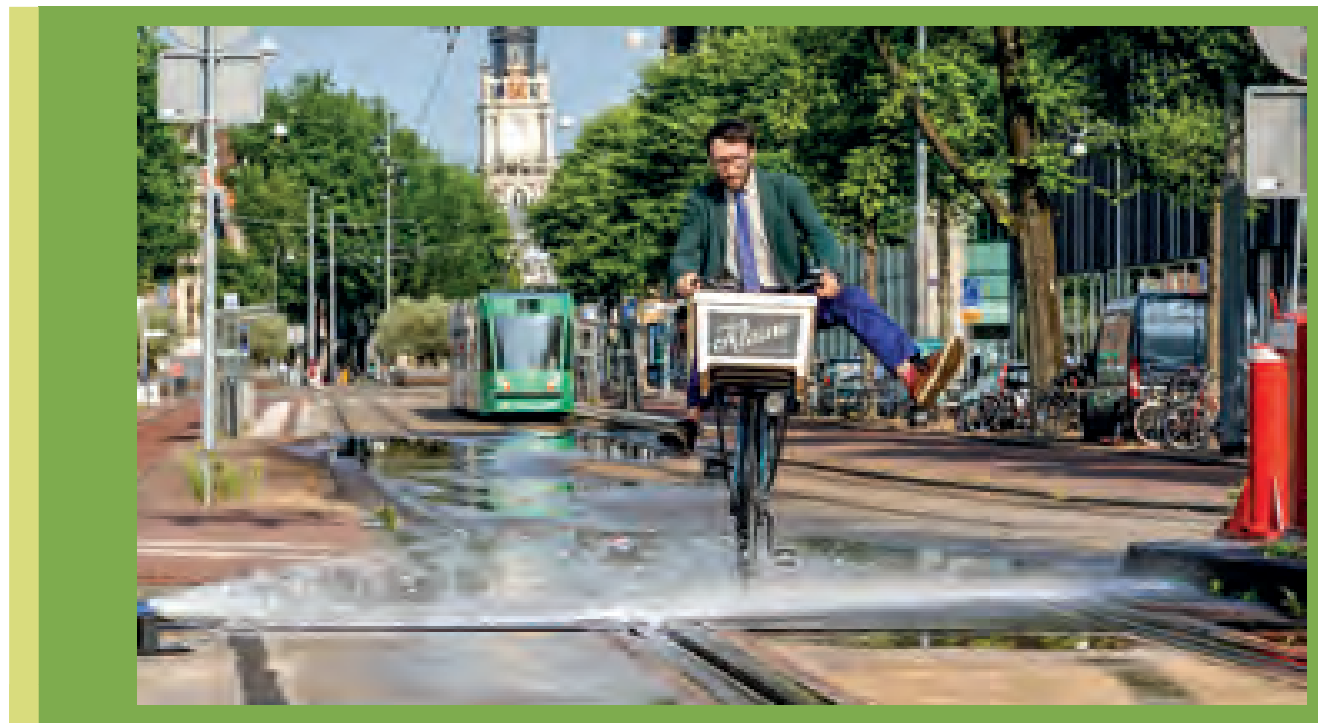

Figure 1.1: Amsterdam streetscape.

I see a man on a bike pulling up his legs to avoid the water staining his pants. He is not using the bike lane, but instead takes the risk of cycling over the rather slippery tram track. Behind him, a tram stops at a station near the Waterloo square in the city center of Amsterdam. I see the historic architecture of the Zuiderkerk that was built in 1611 as the first reformed church. The green trees reveal that this picture must have been made in spring or summertime, when Amsterdam is usually crowded with tourists, but none are portrayed in this picture. The biker's aesthetics - the skinny tie, low but colored socks, vintage glasses and a nonchalant beard - remind me of what some would call a 'hipster'. The crate on his bike is a typical Amsterdam artifact. The picture also hints at a world that cannot be observed with the naked eye: the network of pipes and cables that supply the city's population with water and electricity, or 
the pollution in the air threatening biodiversity. The same picture also awakens

more critical considerations: is this a representative picture of the Amsterdam

population? Who belongs in Amsterdam? May the detour from the bike lane

reveal a lack of cycling infrastructure? How does the local government maintain

its infrastructure and balance between trams, bikes, boats, pedestrians, and

cars? And what about the historic architecture in the back - who is able to afford

the city center since the rise in tourism and property developments? Which

species are inhabiting those leafy trees? Are they threatened?

These observations and subsequent questions could be asked by urban researchers from a wide variety of fields. The field of urban studies is an interdisciplinary field by nature. Cities around the globe are dealing with complex challenges like rapid expansion, increasing crowdedness, intersecting forms of diversity, and staggering inequality between the rich and the poor. These processes take shape in the context of a climate emergency, biodiversity loss, globalization, and unprecedented urbanization. These multifaceted and complex challenges require researchers to move beyond disciplinary boundaries and approach urban problems and solutions via interdisciplinary approaches.

An interdisciplinary approach is uniquely positioned to inform urban governments who are up to the complex task of developing policies and designing interventions that are inclusive, multifaceted, intelligent, and sustainable, but also resilient and adaptable to unexpected change. Urban scholars can contribute to these tasks by unravelling complexity, revealing unequal power relations, or identifying potential solutions using technological or social innovations. Such cooperation with governments and other societal stakeholders pushes the interdisciplinary nature of the field to a transdisciplinary approach that urges scientists to take responsibility for contributing to societally relevant questions, to step outside of academic boundaries and engage professionals and citizens in their research projects.

The persistent and urgent problems cities currently face demand both scholars and practitioners to make better sense of what is going on in the city. To do so, they need methodologies that help them to collect and analyze a diversity of urban data in a diversity of ways, and to integrate and combine these different analyses. This book offers a wide variety of quintessential urban methodologies developed, used, and reflected on by Amsterdam-based researchers. As the editors of this volume, we curated a selection of methodological approaches that we believe will help urban researchers but also practitioners to better understand the multifaceted problems and opportunities of the urban environment. ${ }^{\text {I }}$

I This book includes a selection of methodologies that we believe provide a broad and multidisciplinary overview of the dominant methodologies used in urban studies. We realize that the book is by no means exhaustive of all urban methodologies, and indeed that it cannot be. In the concluding chapter, we return to this point. 
Some research starts with a theory or concept that provides a possible explanation or a hypothesis. Other research starts with a methodology. Often, researchers use a combination of these things: they have a certain methodological and theoretical expertise and observe what is going on in the city, they see real-world problems that they care about and start imagining a research project based on those observations and their specific background. To structure the process of setting up a research project, we propose four central questions:

1 What do I see?

2 How can I understand?

3 What do I miss?

4 Why does it matter?

The first and last questions are highly interrelated, since what we see is usually strongly related to what we care about. The text box above gives a range of possible answers to the first question. Starting with figure I.I, the question 'What do I see?' moves the viewer through various disciplinary avenues that all provide a different view and observe different aspects of an urban streetscape. The final question could be answered personally - why do you care about this topic? But a good research proposal also includes a broader discussion of the societal and academic relevance of a certain research question. The academic relevance of a question is related to other research in and beyond the field. What does the research add to the current state of knowledge? The societal relevance of a given project is highly dependent on contextual factors. How does the research distinctively contribute to making that place, process, or socio-economic or political dynamic - and perhaps other places, processes, or dynamics - better? In the conclusion to this volume we reflect more on the relevance of various forms of urban research.

The first section of this volume answers the question 'What do I see?' by providing various methodologies to gather data. It offers ways to decide which methodologies are most suitable for collecting the data that you need to answer your questions. The second section of the volume answers the question, 'How can I understand?' Here you'll find methodologies for analyzing your data in the context of the city. We distinguish between methodologies for data collection and methodologies for data analyses, to prevent repetition. The same methodologies for data collection statistical data, ethnographic data, interview transcripts, archival data, sensory data - can be used for various methodologies of data analyses. The distinction, however, is not so easy to make in reality because the processes of collecting data and analyzing data overlap and go hand in hand as the research progresses.

The third question, and third section of the volume, requires researchers and professionals to critically reflect on their approach and data. It asks to reflect on what it is that you do not see when you use a certain methodology. Any methodology is a tool that helps to see something in detail but will also and inevitably overlook something else. The clearest example of this is between qualitative and quantitative 
studies. Qualitative research aims at detailed insights into the why and how of processes. A qualitative study could, for example, help develop deep understanding of the everyday experiences and unintended practices of institutional racism. This could make visible why and how institutional racism still jeopardizes the full participation of other ethnic or racial groups in a society or organization. The same study, however, would be missing the actual numbers of instances of institutional racism. These numbers might be necessary to convince leaders that racism is taking place in their organization at a significant scale. Quantitative analysis can provide those numbers. Quantitative research aims at statistically identifying relationships. Quantitative data analysts could provide the necessary numbers and may even prove a relationship between the number of colleagues of color and the lack of promotions among them. Those statistics alone, however, do not explain how and why this is the case. Qualitative analysis can help here. Although it often occurs in a more nuanced way than in this example, all methodologies focus on something and leave out something else. We therefore asked each author of the volume to reflect with us on the question 'What do I miss?' when applying their methodology. Next, we invited them to think how their different approaches could complement each other and be integrated towards new forms of knowledge. Section three is the result of that journey and offers practical guidelines for researchers and practitioners who are willing to cross disciplinary boundaries, and boundaries between academic disciplines and non-academic knowledge.

\section{Seeing the city}

Before we can proceed to the methodologies discussed in this volume, we must reflect on the way we see - that is, that crucial first question. First, because the kinds of observations we make as researchers are closely related to the disciplines in which we are educated. Second, because the way we see the city and formulate problems and methodological solutions is closely related to the paradigm we employ. Being aware of those is key for being able to position and value a particular view relative to other possible views.

\section{Seeing the city through different disciplines}

A discipline could be explained as a pair of glasses. If the shades are red, they emphasize the red tones in the picture and the viewer would have more difficulties seeing the yellow or the blue, and the other way around. If we put on these metaphorical glasses to view the image above as urban anthropologists, we see a man employing a tacit cycling practice; it could tell us something about the unwritten rules of cycling culture in Amsterdam. Such observations are usually the product of ethnographic research that builds on in-depth and real-time experiences. If the ethnographer did not research infrastructure management, her uninformed eye might believe that the image portrays a flood. It might make her wonder whether Amsterdam is the victim of quickly rising water levels and climate change. To understand the picture better she needs to include the knowledge of an infrastructure planner who knows that, in the summer, local infrastructure management pumps water out of the canals onto the bridges so that they do not 
expand due to the heat. Infrastructure planners, however, might not notice the tactics of the biker pulling up his legs and instead focus only on the streetscape and interconnection of bike lanes, water ducts, tram tracks, street markings, and traffic signs. Triggered by the peculiar tactics of the biker, a data analyst would critically wonder why and how often people detour from the bike lane, and employ sensory data to calculate how many accidents might be avoided with a better street design.

Looking at the same picture from a historical perspective would reveal the story of the first Protestant church in the city, the burial of Rembrandt van Rijn's first child and the baptism of his fourth, or the church's relevance to the care for orphans mid-seventeenth century. A cultural heritage expert might research its architectural value, an economist the increase in surrounding properties after the investment in cultural heritage. Geographers might use similar quantitative data to analyze the more general process of gentrification these areas of Amsterdam underwent in the past few decades. The eyes of cultural studies experts would be drawn to the aesthetics of the man and his bike, which may be used to critically read the discourse of this picture. Meanwhile, the biologist would sharpen her eyes and ears to observe and listen to the variety of birds singing in the trees. Action researchers and designers might be drawn to this rather confusing site to engage in a streetlab or experiment with municipal actors and citizens using this space to learn about effective and inclusive interventions.

As this carousel of viewpoints suggests, the discipline in which researchers and practitioners are educated shape their way of seeing the city and the problems they identify. Seeing something beyond your discipline is a challenge - usually it does not come naturally and thus requires work and perseverance. That challenge is even stronger if you try to look from the perspective of a discipline that uses a different paradigm to make sense of the world.

\section{Seeing the city through different paradigms}

All research projects and questions are embedded in a certain paradigm. A paradigm is a set of beliefs that shape the way you make sense of the world. It represents a worldview that defines, for its holder, the nature of the 'world' (Guba \& Lincoln, I994, p. I07). Guba and Lincoln (I994) distinguish between four basic paradigms in the sciences: positivism, post-positivism, critical theory, and constructivism. These paradigms, albeit often unconsciously, shape the way researchers understand the nature of the world (ontology), how we think we can know that world (epistemology), and finally the way we formulate questions and organize to research the world via methodologies, the purpose of the project, and the relationship between the researcher and the field. (For further reading on ontology, epistemology, and methodology see Guba \& Lincoln, I994). The main tension between these four paradigms exists between positivism or post-positivism on one side, and critical theory or constructivism on the other. 
In a nutshell, positivist or post-positivist paradigms present a worldview that assumes that the world is an external objective reality that is apprehensible via objective findings that explain how things 'really work'. The difference between positivism and post-positivism is that the latter still assumes an objective reality, but grants that the understanding and study of that reality is always imperfect and approximate. The methodologies used by positivist and post-positivist researchers are often, but not always, quantitative. In this paradigm, the researcher is seen as independent from what is researched, and it is assumed that the researcher does not influence the field of research. The outcomes of this type of research usually verify or falsify a hypothesis in order to prove, predict, or control something. Chapters 2 and 4 provide a more in-depth discussion about quantitative data collection.

Researchers employing a critical or constructivist paradigm, on the other hand, see the world as inseparable from themselves: they refuse an 'objective' truth, and assume that our world is constantly subject to change. For critical theorists, that change is shaped by historically situated structures, while for constructivists the world and all its related meanings or structures are a product of human intellect, and thus always under construction and often contested. They assume that there is no single truth that can be known and that knowledge itself is value-mediated and therefore dependent on the researcher, the historical context, or the interactions among researchers and the field. They often, but not always, use qualitative methodologies that represent conflicting interpretations, dialogical and dialectical constructions. The goal of this type of research is not to prove or predict something, but to critique and transform (in critical theory) or to understand and reconstruct (in constructivism) a given process or phenomenon. Chapters 3 and 5 delve deeper into the collection of qualitative data, and chapter 6 into collecting historical data.

Paradigms also shape the ways in which the quality of research findings ought to be assessed. The main criteria for determining the quality of findings are objectivity, reliability, and validity, as derived from experimental-statistical hypothesis testing (Flick, Kardorff \& Steinke, 2004, p. I83). There is much debate about whether or not these positivist, quantitative criteria should be transferred to critical, qualitative research. Positivist, quantitative research is based on the premise that there is one objective reality (developing objectivity), the relationship between the researcher and the object is independent (strengthening reliability), and the nature of truth to a finding can be assessed (validity of findings). On the other hand, critical, constructivist, qualitative research rejects the idea of an objective reality and thus does not aim at developing objectivity. The relationship between the researcher and the object can never be objective since data is developed in close interaction with the field and the people in the field. Finally, the outcomes are oriented to providing descriptions, analyses of processes or behavior, or critical reflections, rather than one truth. To assess the trustworthiness of qualitative research, some qualitative scholars use triangulation. Some propose using criteria such as the credibility of the findings and argumentation; transferability (to rethink how the findings hold in some other context); and dependability and confirmability (by auditing the research process 
via fieldnotes, interview transcripts, data analysis decisions) (Anney, 20I4; Flick, Kardorff \& Steinke, 2004). Because paradigms are so radically different, researchers should rethink which quality criteria can best be applied to their projects. They argue that a misuse of criteria or the application of quantitative criteria to qualitative research - or the other way around - poses critical problems and curtails the development of credible and valid outcomes (Leininger, I994, p. 96).

In this volume we do not favor one paradigm over another: the methodologies discussed in section two have qualitative and quantitative roots and employ all paradigms discussed by Guba and Lincoln. We also do not take a stance in the debate on which quality criteria to use, but we urge all researchers to reflect on this issue and actively choose which criteria you will apply to your findings. Quality criteria, trustworthiness, and limitations of each methodology are discussed in the context of each methodological chapter. For a more general discussion of how quantitative data is verified you can continue reading chapter 2 , and for qualitative data you can read chapter 3. For further reading on this debate see Anney (20I4); Flick, Kardorff and Steinke (2004); van de Port (20I7).

\section{Paradigms and research questions}

The paradigm a researcher or practitioner adopts also shapes the way they ask questions. From the description above it might be clear that positivists and post-positivists usually ask questions that allow them to test a hypothesis. That means that they often formulate research questions that aim to generate an objective and often statistical outcome. Common formulations of such research question start with 'To what extent...?' or 'What share of ... leads to ...?' or 'What is the impact of ... on ...?' Chapters 2, 4, 9, II, and I2 of this volume provide examples of methodologies using these kinds of research questions.

Researchers using a critical or constructivist paradigm are more prone to ask questions that generate an analysis of the reasons behind a certain process or phenomena, formulated as a 'why' question. They may also try to understand the unfolding of or the dynamics within a process using 'how' questions. Or, when they seek to understand things that are rather uncommon or unknown, they might use descriptive questions that are often formulated as 'what' questions. Chapters 3, 5, 6, 7 , and 8 describe research projects that used these kinds of questions.

Finally, there are research questions that are oriented to making an intervention and creating change. These applied questions often include a certain normativity of what could or should be improved and the projects are focused on researching how these interventions can take place, and to what effect. Chapters 4 , I3, and I4 in this volume illustrate such change-oriented research projects.

\section{Seeing Amsterdam}

The city of Amsterdam is the case study that runs through this volume to illustrate the way researchers execute their methods, make choices, and develop insights. The 
choice of Amsterdam has practical as well as more principled reasons. First of all, the Center of Urban Studies (CUS) at the University of Amsterdam brings together a broad group of interdisciplinary scholars using a wide variety of methodologies to study the city. We wanted to tap into this existing network and make use of the knowledge and practices that these scholars have to offer to the field of urban studies. Second, we set out to establish more cooperation between CUS and an even larger group of scholars and professionals from related universities, research institutes, and the municipality of Amsterdam. Our search led to a transdisciplinary collection of authors who are at the forefront of urban research, theory and practice. The authors are all situated in Amsterdam for either work, life, research, or a combination of these things, and know the city by heart. By seeking local contributors, we were able to facilitate a process of workshops in which authors developed a transdisciplinary community of urban research.

We believe that seeing and understanding the city can never take place through only one perspective. The main purpose of the volume is to provide hands-on practices to view the city and its real-world problems from various points of view. The book offers I5 unique ways of seeing and understanding the city and each chapter offers another perspective on the city of Amsterdam. That way, the added value of seeing one city through a multitude of perspectives becomes visible and tangible in the case of Amsterdam.

We hope that these reflections on Amsterdam inspire both urban scholars and practitioners to apply these methodologies to their own urban context.

\section{Seeing this volume}

The four main questions that structure this volume - 'What do I see?', 'How can I understand?', 'What do I miss?', and 'Why does it matter?' - also provide an approach to setting up a problem-based urban research project. Section one includes chapters on quantitative data gathering (via census, survey, or big data), ethnography, sensory data, interviewing, and archival research. Section two provides chapters on cultural analysis, institutional analysis, economic analysis, historical simulation, spatial analysis using Geographic Information Science and Systems), analysis of urban biodiversity, action research, and research through design. All these chapters explain the goals, techniques, choices, and limitations for gathering data or analyzing those data. Each chapter in the volume provides two types of text; the main text explains the respective methodology in general terms and the textboxes discuss how the researcher has applied these methods to the case study of Amsterdam.

While developing this volume we became aware of the multiple audiences this book might have. We did our very best to cater to these different audiences and devise a volume that could function as a work of reference for readers with different needs. Therefore, we offer our various readers a guide for how to use this book. 
If you are an urban scholar or professional looking for methodological avenues to study the city, we invite you to carefully think through what it is you see, consider how you approach what you see through paradigms, and start imagining a research question about what you see. Sequentially, you can read all relevant methodological chapters and the textboxes to learn how the various methods are applied, how choices were made, and what results came out of these studies.

If you are a professional from the municipality of Amsterdam, another local organization, or a citizen and you are mostly interested in the outcomes of various research projects that took place in Amsterdam, you could decide to focus your reading on the textboxes that illustrate each methodology and provide an array of findings, ranging from studies of gentrification (chapters 2 and 6), to the question of ownership (chapters 3, 5, 7, 8, II, and I2), and the analyses of spatial flows and designs (chapters 4, II, I3, I4, and I6).

If you are a scholar of interdisciplinary studies and your key interest is to understand the process of developing such an interdisciplinary book, we propose you start reading chapter $\mathrm{I} 5$, in which myriad possible forms of integration between methodologies are discussed. This discussion reveals the possibilities and difficulties of interdisciplinary processes but also offers hands-on practices to successfully mediate such process. Based on your interest, you can work your way back to the various methodological chapters in the volume. And finally, you could read our own reflections on establishing this volume and the missing methods in the conclusion.

If you are an urban professional or citizen and you would like to better understand how the city, the municipality, and other organizations can work together in a transdisciplinary team, we propose that you start by reading chapter $\mathrm{I} 6$, which discusses the potential and difficulties of such an endeavor. After that, you might be interested in reading chapters $\mathrm{I} 3$ and $\mathrm{I} 4$, which also provide engaging examples and practical strategies for transdisciplinary research.

For all other readers who do not fit in one of these categories, we hope that this introduction has provided you with some ways to navigate our volume. We wish you much inspiration and welcome you in the ongoing dialogue about the complex but endlessly engaging environment that we call the city. 


\section{References}

Anney, V. N. V. (2014). Ensuring the quality of the findings of qualitative research: Looking at Trustworthiness Criteria. Journal of Emerging Trends in Educational Research and Policy Studies (JETERAPS), 5(2), 272-281.

Flick, U., Kardorff, E. von., \& Steinke, I. (2004). A companion to qualitative research. London: Sage.

Guba, E. G., \& Lincoln, Y. S. (1994). Competing paradigms in Qualitative Research. In N. K. Denzin \& Y. S. Lincoln (eds.), Handbook of Qualitative Research. London: Sage, pp. 105-117.

Leininger, M. (1994). Evaluation criteria and critique of qualitative research studies. In J. M. Morse (Ed.), Critical issues in qualitative research methods. London: Sage, pp. 95-116.

van de Port, M. (2017). The verification of ethnographic data: A response. Ethnography, 18(3), 295-299. 